\title{
Media Reportage and Audience Perception of Hepatitis Disease in Nigeria
}

\author{
Adesina Evaristus A. ${ }^{1}$, Okorie Nelson ${ }^{1}$, Oyero Olusola ${ }^{1}$, Adeyeye Babatunde $\mathrm{K}^{2} \&$ Oyesomi Kehinde ${ }^{2}$ \\ ${ }^{1}$ Department of Mass Communication, Covenant University, Ota, Nigeria \\ ${ }^{2}$ Department of Mass Communication, Covenant University, Ota, Nigeria, Covenant \\ Correspondence: Okorie Nelson, Department of Mass Communication, Covenant University, Ota, Nigeria. E- \\ mail: nelson.okorie@covenantuniversity.edu.ng
}

Received: July 19, 2017 Accepted: August 23, 2017 Online Published: August 28, 2017

doi:10.5539/gjhs.v9n10p68 URL: https://doi.org/10.5539/gjhs.v9n10p68

\begin{abstract}
The growing incidence of hepatitis disease has become a perennial issue across the globe. Healthcare providers and communication experts agree that hepatitis disease is a highly infectious and deadly disease that has infected several millions of individuals in high and low-resource countries. This study examined the media reportage of hepatitis disease as well as the perception of Nigerians on the awareness and knowledge of the disease. This study was anchored on the Health Belief Model (HBM), which explains how attitude of individuals can be influenced by media and health communication messages. This study adopted a dual research method that made use of survey and content analysis to achieve the objectives of the study. The results indicated that $53.3 \%$ of the respondents had been previously informed about the hepatitis disease, with only 62 people getting to know through the mainstream media (television, radio and newspaper) and 42 people were informed through the internet (the new media). The study further revealed that just 55 stories were published in duo years of 2015 and 2016 by four national newspapers in Nigeria. This study recommends that the media in Nigeria need to urgently align with the Health Belief Model (HBM) by positively affecting the perception of the people to live a sensitive and conscious life against the hepatitis disease.
\end{abstract}

Keywords: disease, hepatitis, media reportage, Nigeria and perception

\section{Introduction}

The pandemic nature of the hepatitis disease in Nigeria is fast getting out of control. Reports from the Centre for Disease and Aids Control revealed that one in every ten Nigerian citizens is infected with the disease which is deadlier than Human Immunodeficiency Virus and Acquired Immune Deficiency Syndrome (HIV/AIDS); more so, carriers of this disease are largely oblivious of its existence and its consequences (Agada, 2016). Hepatitis infection is widely referred to as a silent killer because many carriers do not realize they are carrying the virus, even to the extent of 10 years (Seef, 1999; Libbus \& Phillips, 2009). Blumberg (2002) submits that hepatitis records a large mortality both from acute infection and chronic disease conditions and is positioned among the ten top killer diseases.

Beyond being a national issue, the hepatitis disease has become a global concern as the World Health Organisation (WHO) observes that over 400 million people are currently living with the disease. WHO further estimated death rates from hepatitis related diseases is up to 1.4 million per-year, which is similar to HIV and tuberculosis (World Health Organisation Report, 2016). The goal 3.0 of the Sustainable Development Goals (SDGs) as set by the United Nations General Assembly on the $25^{\text {th }}$ of December, 2015, which is to ensure healthy lives and promote well-being for all ages by the year 2030. More specifically, the goal is set with the objective of putting an end to the epidemics of AIDS, tuberculosis, malaria and neglected tropical diseases as well as combat hepatitis, water-borne diseases and other communicable diseases (WHO, 2016).

Nugent (2006) notes that there are more youth in the world now than ever before, and they are concentrated in developing countries to which Nigeria belongs. The population of Nigerian youths (15-35 years) according to the 2012 report of the Nigerian Bureau of Statistics is 64 million. The transmission nature of hepatitis disease therefore, cannot be divorced from the experimentation and exploration characteristic of youths. The success or failure of any development program is largely directly and indirectly tied to the functionality of youth. The National Youth policy and strategic plan of Nigeria (2001) recognises the foundational nucleus of youth to the 
growth and development of any society. The policy observes that embedded in dreams and hopes of the youth, a nation finds her motivation and on their energies, she builds her vitality and purpose.

The day-to-day exposure of youth to numerous health challenges, especially the silent killer hepatitis, therefore necessitates an urgent need to examine the awareness and knowledge level of the viral disease among youths in relations to media coverage of same. Scholars such as (Mowlana, 2000; Okorie, 2011; Oso, 2012; Okorie, Oyesomi, Oyero, Olatunji, \& Soola, 2014) have the same opinion that there is an underlying relationship between the mass media and the society. In view of the fact that the mass media are transmitter of messages from sources to receivers, they owe society, principally the youth in this context. The media have the responsibility of generating awareness and knowledge about hepatitis deadly disease. It is this type of thinking that made Okorie et al., (2014) to assert that the definite and probable roles of the mass media have long been acknowledged and recognized to have the capability of enlightening heterogeneous audiences about diseases such as hepatitis. Thus, the mass media serve as a crucial purveyor of health information in any modern society.

From the foregoing, the silent but prevalent nature of the hepatitis disease now calls for greater concern across borders of human ecology. Despite the global burden of the viral disease, little emphasis has being placed both as a health and a development issue (World Health Organisation Report, 2016). There is therefore a need to align with the recently launched "Global Health Sector Strategy on Viral Hepatitis", a plan developed to engender a quick and effective achievement of the 2030 Agenda for Sustainable Development. The strategy focuses on eliminating the infectious viruses of Hepatitis. This study therefore, seeks to find out the media coverage of Viral Hepatitis Disease in correlation with the awareness and knowledge level of the disease among Tertiary Institution students in Ogun State.

\subsection{Objectives of the Study}

1) To examine the extent of coverage given to Hepatitis disease by selected newspapers in Nigeria.

2) To find out the awareness level of students in Ogun State tertiary institutions about the hepatitis disease.

3) To determine the knowledge level of hepatitis disease among students of Ogun State tertiary institutions.

\subsection{Research Questions}

1) What is the extent of coverage given to Hepatitis disease by selected newspapers in Nigeria?

2) What is the awareness level of Students in Ogun State tertiary institutions about the Hepatitis disease?

3) What is the knowledge level of Hepatitis disease among students of Ogun State tertiary institutions?

\subsection{Theoretical Framework}

This study is anchored on the Health Belief Model to understand the nature and danger of Hepatitis disease in Africa. The Health Belief Model (HBM) is largely the most regularly used theory in health education and health promotion (Glanz, Rimer, \& Lewis, 2002; National Cancer Institute [NCI], 2003).

The Health Belief Model (HBM) is a model of psychology which explains and predicts health behavior. This is achieved through a critical focus on the attitude and belief of individuals. The core concept of the original HBM according to Hochbaum, (1958), is that health behavior determined by personal beliefs or perceptions about a disease and the strategies existing to decrease its occurrence. Such strategies that determines the perception is the media. The action and inactions of the people towards Hepatitis disease therefore is largely determined by a modifying factor such as the extent of information and quality of such made available by the media. In other words, the mass media can create awareness and knowledge about the danger of Hepatitis disease to positively influence the behavior and beliefs of individuals in the African society. Furthermore, the mass media can serve as a pivotal health communication vehicle to influence behaviours of individuals to engage in practices that prevent and curb the growing incidences of the disease.

\subsection{Global Overview of Hepatitis}

In a foreword written for the 2013 Global Policy Report on the Prevention and Control of Viral Hepatitis in WHO Member States, by the World Health Organisation Director General, Margaret Chan posited that the hepatitis disease is "responsible for a widely prevalent and growing disease burden", submitting that "no country, rich or poor, is spared". The problem of viral Hepatitis in Nigeria is however complex to quantify precisely, because of insufficient demographic data and paucity of scientifically sound research (Nimzing \& Simon, 2005).

The Centre for Disease Control (CDC) (2016) defines Hepatitis Disease as a situational inflammation of the liver organ. The liver which is the largest and very fundamental organ in the human body processes nutrients, filters the blood, stores energy and fight infections. When the liver is inflamed or damaged, its function can be affected. 
Hepatitis therefore connotes the infection or inflammation of the hepatocytes, as evidenced by abnormal Liver Function Tests (LFTs) (Hall, 2007).

In the submission of Golla, Epstein, and Cabay (2004), Hepatitis majorly occurs through the infectious and noninfectious means. On the one hand, alcohol, prescription medications, and drug abuse are predominant noninfectious causes, while viruses and bacteria are key infectious causal factors. On the other hand, they noted that viruses and bacteria are important infectious causes of Hepatitis. The viral Hepatitis disease has being classified into 6 distinct types namely A, B, C, D, E and G with different modes of transmission, affecting different people.

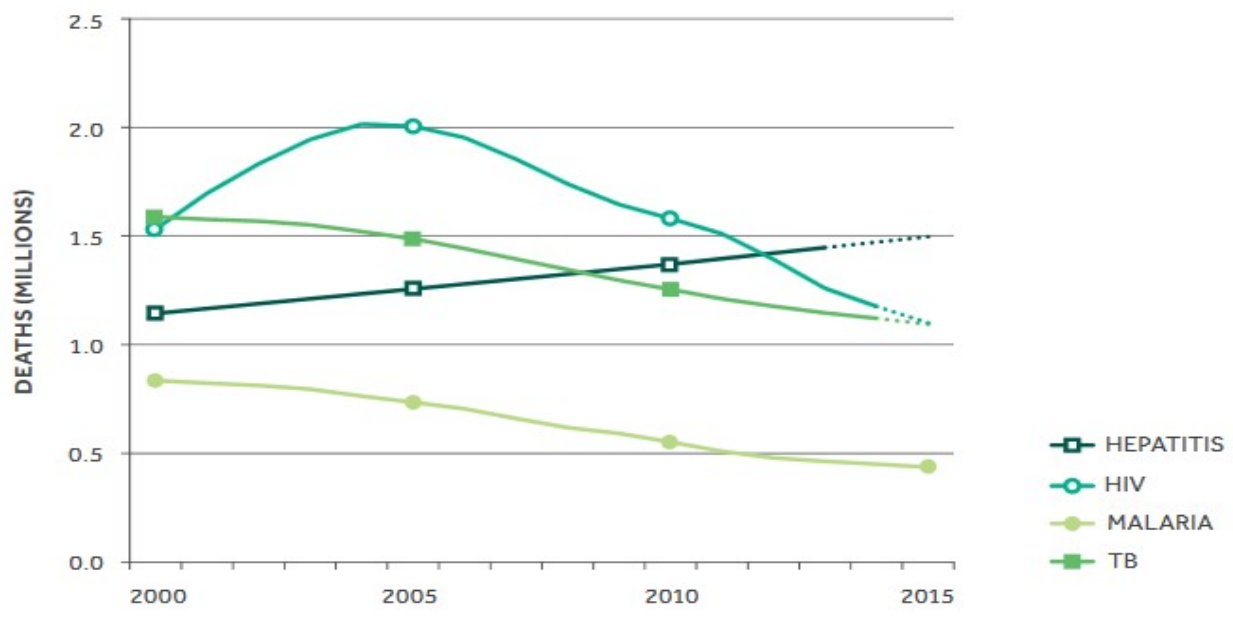

Source: Global Burden of Disease and WHO/UNAIDS (2016)

1) Hepatitis $\mathbf{A}$ is highly contagious, but rarely deadly liver disease caused by infection with the hepatitis $\mathrm{A}$ virus (HAV). Pischke and Wedemeyer (2016) described the HAV as a global infection, occurring either sporadically or in epidemic outbreaks, with an approximate 1.4 million cases yearly. Out of this, the developing Nations are said to have the largest share. The virus is said to be spread through the ingestion of fecal matter (waste product), even in microscopic amounts from contact with objects, food, drinks stool from an infected person. CDC (2015), in its report further identified some ways to contract Hepatitis A to include: (a) non or improper hands wash after toilet usage (b) changing diapers or cleaning up the stool of an infected person (c) Sexual engagement with an infected person

2) Hepatitis B- One third of the global population has blood evidence of hepatitis B virus (HBV) (Mohr, Boesecke and Wasmuth 2016). Studies have revealed HBV to be more common in developing nations to the tune of $8 \%$ as a result of sex, age and economic factors (OdusanyaAlufohai, Menrice, Wells, Weil and Ahohkhai 2005; Akikor and Erhabor, 2007). Burnett, Francois and Kew (2005) stated that Sub-Saharan Africa has a high endemicity, and more than 50 million people were affected by the disease.

3) Hepatitis C- Hepatitis C (HCV) is most commonly spread by exposure to contaminated blood or needles. In the submission of WHO (2015), an estimate of $130-150$ million representing $2 \%-2.5 \%$ of the world's population are chronically infected with the hepatitis $\mathrm{C}$ virus (HCV). Chronic HCV infection is normally a slow but continuous silent killer with minor or no symptoms after infection for many years (Golla et al., 2004). Eighty-five percent of patients with HCV will develop chronic hepatitis (Wisnomand Siegel, 2003). Boesecke and Wasmuth (2016) identified the following has some of the transmission means of $\mathrm{HCV}$ : injection drug use, blood transfusion, sex with an intravenous drug use, cut with a bloody object, piercing and immunoglobulin injection

4) Hepatitis D- Hepatitis D Virus uses the HBV surface substance as a viral cover (Golla et al 2004), consequently patients with HDV are dually affected with HBV. The spread of HDV can occur via infected blood and is primarily seen in people who use intravenous drugs and hemophiliacs. HDV which currently has no effective antiviral treatment has approximation of 15 million people across the World chronically co-infected with HBV (WHO 2016). The transmission mode of HDV is mostly through sexual activities (Hall 2007). In some settings however, the increase of hepatitis D prevalence has been seen in persons who inject drugs or as a result of migration from areas where HDV is endemic 
(WHO 2016).

5) Hepatitis E- Hepatitis $\mathrm{E}$ is a condition of liver inflammation which occurs as a result of hepatitis $\mathrm{E}$ virus (HEV) Pischke and Wedemeye (2016). Every year, according to WHO (2016) there are an estimated 20 million HEV infections worldwide, resulting to an estimated 3.3 million symptomatic cases of hepatitis E. Approximately, 56,000 people are said to be dying yearly of HEV globally. Just like hepatitis A, HEV is a self-limiting, transmitted disease however more severe and easily transmitted (Pischke, 2013). HEV has been considered to be a travel-associated, acute, self-limiting liver disease that only causes fulminant hepatic failure in specific, high-risk.

\subsection{Mass Media and the Danger of Hepatitis}

Convincing people to agree to healthy manners and behaviors of policymakers as well as Government to initiate and change practices in support of better health has never been an easy task, especially in a one world separated in race, culture, language and belief but connected in health issues. The need therefore for health communication cannot be overstated. Health communication is one of the many strata of communication discipline with the objective of bridging the information gap in the society. Recognizing its imperativeness, (Clancy, quoted in Krisberg, 2004) described health communication as the "the main currency of healthcare in the 21 st century". More specifically, the Centers for Disease Control and Prevention (CDC) sees health communication as "the study and use of communication strategies to inform and influence individual and community decisions that enhance health" (U.S. Department of Health and Human Services, 2005).

Key words such as; "influencing individuals or communities" (Freimuth, Linnan, \& Potter, 2000, p. 337, Freimuth, Linnan, \& Potter, 2000, p. 338), "informing"(CDC, 2001; U.S. Department of Health and Human Services, 2005),"motivating target audiences," "exchanging information," and "changing behaviors"(Clift \& Freimuth, 1995, p. 68) are some of the characteristics attached to health communication.

The central function of the mass media in the achievement of "The Global Health Sector Strategy on Viral Hepatitis 2016 - 2021" as launched by the World Health Organisation cannot be over stressed. The new vision is poised towards ending the viral hepatitis disease and the achievement of the 2030 health agenda of the Sustainable Development Goal (SDG).

The strategy according to World Health Organisation has the vision of "a world where viral hepatitis transmission is halted and everyone living with viral hepatitis has access to safe, affordable and effective care and treatment; eliminating viral hepatitis as a major public health threat by 2030; reducing the incidence of chronic hepatitis infection from the current $6-10$ million cases of chronic infection to 0.9 million infections by 2030, and to reduce the annual deaths from chronic hepatitis from 1.4 million to less than 0.5 million by 2030 . Achieving these targets will require a radical change in the hepatitis response, and will mean that hepatitis is elevated to a higher priority in public health responses" (WHO, 2016, p. 7).

"Strategic direction 1 - Information for focused action: developing a strong strategic information system to understand viral hepatitis epidemics and focus the response" (WHO, 2016, p. 7).

The first directional goal as developed by the World Health Body confirms the nucleus function of the media. The media has great power to direct thoughts towards societal issues including health. This is related to the position of Cohen (1963) having revised the Agenda setting theory of McCombs and Shaw that "the media may not be successful much of the time in telling people what to think, but it is stunningly successful in telling readers what to think about" (p. 13).

Lasswell (1960) delegated to the mass media three major roles for the society within which they operate: surveillance, correlation, and transmission of cultural heritage from one generation to the next. In the context of this study, the media has a critical function beaming its searchlight in the health sector for adequate dispensation of the right information to both citizens and policy maker. In addition, Bryant and Thompson (2002) have suggested that news coverage of health matters takes on substantial implication, that has the potential to affect and influence the sense of understanding of an average citizens on the one hand and powerful policy makers on the other hand.

Newspaper has been proven to be a veritable and credible medium of health information to keep away from health risks and to live a more healthy life style (Atkin \& Wallack, 1990; Kreps \& Thornton, 1992; DuttaBergman, 2004). This justifies Oyero (2010) submission that the print media functions in development process by ensuring persuasion, motivation, providing learning materials and appropriate development information for educated members of the society. 


\subsection{Vulnerability of Youths to Hepatitis Disease}

The vulnerability level of youths to contracting hepatitis cannot be overstated as a result of the high risk factors of the disease and the eccentric behavioral patterns of youth. Although there are numerous definitions of youth, however the United Nation Youth Agenda (2004) describes people between the age range of 15 and 24 years of age as youths. These set of people constitute $18 \%$ of the World Population with over 1.2 billion people. The energetic sense of a youth is further depicted in the definition of Ibezim et al. (2010) that a youth is a stage in one's life when one is agile, energetic, determined and adventurous in experimenting different perspective of life.

The strength of youths if not efficiently utilized makes for high susceptibility to health risk. This is seen in the data presented by the World Health Organisation that yearly, 2.6 million young people dies (W.H.O, 2011). Among the causal factors of these deaths includes; unintended injuries and violence, mental and neurological conditions, nutrition, alcohol and illicit drug use (W.H.O, 2011).

The high risk factors attributable to hepatitis on the one hand and the vulnerability of youth on the other hand therefore explain the need for the mass media to effectively and strategically provide hepatitis information in order for tertiary institution students as examined in this study be knowledgeable and informed.

\subsection{Empirical Review}

In the field of health communication, there have been several studies on the nature of Hepatitis disease in Nigeria and the world. In a study conducted by Samuel, Aderibigbe, Salami, and Babatunde (2009) amongst health workers of diverse cadres at Irrua Specialist Teaching Hospital, located in Irrua, a community in Essan Central local government area of Edo state, Nigeria. The result revealed $81 \%$ of the respondents had never heard of hepatitis B infection. Their study further showed that $70.2 \%$ have received Hepatitis B vaccine, out of which only $59.4 \%$ completed the vaccination calendar.

Another study conducted at the Department of Haematology/Immunology, Ahmadu Bello University Teaching Hospital (ABUTH) Zaria, involving 100 randomly selected blood donors (voluntary and commercial) between the ages of 15 to 60 years indicate a highest prevalence among men (86.6\%) as against women with the prevalence of only 13.3\% (Ado, Alhassan, Chonoko, \& Samalia 2010).

Monzeal-Bistgani and Shahrjerdi (2014) conducted a study on the influence of incorrect customs of lifestyle on Hepatitis disease and infection transmission. The study indicated that some incorrect customs serve as predictive factors that aided infection transmission among persons. Some of these incoreect customs were history of making shallow incisions on the auricle and the exchanging of blood of individuals during childhood. The study concludes that it has becomes important that scholars and health experts pay special attention to implementation in such situation for hepatitis B prevention in the population: effort on increasing the knowledge in the general population.

In the same vein, Mbaawuaga, Iroegbu and Ike (2014) in a study to find out the pattern of occurrence of Hepatitis B among 1535 randomly selected blood samples in Benue State. Of the 1535 sampled individuals, $1319(85.9 \%)$ showed a serological evidence of exposure to HBV infection, some through natural infection $(22.7 \%)$ and others $(13.0 \%)$ through vaccination; $12 \%$ of the exposed were inferred to be currently infected and (91.2\%) chronically infected.

A cross sectional study conducted on one hundred and forty children aged 18 months to 15 years at the University of Nigeria Teaching Hospital children outpatient clinic by Uleanya and Obidike (2015) to verify the commonness of Hepatitis B surface antigen (HBsAg) among children and mothers. The study revealed a gradual fall in the prevalence of HBsAg in our environment due to HB immunization.

As a result of the related transmission means of Hepatitis and HIV viruses, Mustapha and Jibrin (2004) recruited and screened $200 \mathrm{HIV}$-infected individuals comprising 97 males and 103 females for HBsAg. The result revealed that Fifty-three of the patients tested positive for HBsAg giving an overall prevalence rate of $26.5 \%$ which was significantly higher $(\mathrm{p}<0.001)$ than the $10.4 \%$ recorded among non-HIV-infected individuals.

The high prevalence of hepatitis therefore questions the knowledge, awareness and practices of Nigerians. A similar study by Adekanle, Ndububa, Olowookere, Ijarotimi and Ijadunola (2015) on the awareness and knowledge level of hepatitis B virus infection, risk perception, vaccination history, and challenges to control hepatitis among 382 health workers of Obafemi Awlowo University, Ile Ife. While the respondents comprised 94 (25\%) medical doctors, $168(44 \%)$ nurses, 68 (18\%) medical laboratory technologists, and 52 (14\%) pharmacists. Despite the profession of the respondents, the result revealed that over $33 \%$ had poor knowledge with $35 \%$ not immunized against HBV. 
A gap between the awareness and knowledge level of the disease was discovered in the study carried out by Gboeze Ezeonu, Onoh, Okaegbe and Nwali (2015) on pregnant women (400) on antenatal care at the Federal Teaching Hospital, Abakaliki. It was discovered that 258 (62.5\%) of the women have heard of HBV infection. Contrastingly, only $99(24.8 \%)$ knew that hepatitis is a viral infection affecting the liver, $27(6.8 \%)$ thought it is an eye disease while 210 (52.5\%) were not knowledgeable.

In asimilar study, Chen Hung, Chang, Tsai and Chang (2017), conducted a study on the assessment of educational needs and quality of life of chronic hepatitis patients. The study maintained that patient education was important in improving the quality of health lifestyle of individuals in the different cross-sections of a modern society. The study indicated that the quality of life of individuals can be maintained and improved with nursing counseling and intensive education.

In the several studies reviewed, there are several health issues that can be identified and discussed. Some of these issues are (1) low level of knowledge about Hepatitis (2) Hepatitis is strongly interlinked with Human Immune Virus (HIV) (3) incorrect customs about Hepatitis (4) the need for education about the disease. From these interjections, the need for health education about Hepatitis was a salient health issue that pervades the discourse and researches. However, there was dearth of research insight on the role of the mass media as a purveyor of health information on Hepatitis. The mass media can serve as a vanguard

\section{Method of Study}

The study adopted both qualitative and quantitative research methodologies. On the one hand, content analysis was used to find out the extent the Nigerian newspapers have covered hepatitis disease. Four Nigerian newspapers including; the Punch, the Guardian, the Nation and Daily Trust, were purposively selected and issues between January 1, 2015 and September 30, 2016 (21 months) were analysed. The justification for the selection of these newspapers draws from the fact that they are national in outlook, they report health in details (Odoemelam, Okeibunor, \& Okorom, 2016), and for the purpose of comparison. Coding sheet was developed as data collection instrument for the study for an organised data.

On the other hand, the study utilised the survey method to the find out the awareness and knowledge level of hepatitis disease among students in three purposively selected tertiary institutions in Ogun State. Federal University of Agriculture, Abeokuta, MoshoodAbiola Polytechnic, Abeokuta and Federal of College of Education, Osiele, Abeokuta, were the population used for the study. 100 respondents were randomly sampled in each institution, making a total of 300 respondents sampled in the study. The choice of 300 respondents as sample size was hinged on Comrey and Lee's (1992) guideline for selecting a sample size for multivariate studies. This guideline was further adopted by Wimmer and Dominick (2006: 101). The authors recommend that a sample size of " 50 is very poor; 100 is poor; 200 is fair; 300 is good; 500 is very good and 1000 is excellent". Also, the high risk factor of the hepatitis disease cum the eccentric nature of youths formed the basis for the selection of students in tertiary institutions in Nigeria.

\section{Findings and Discussion}

Research Question 1: What is the extent of coverage given to hepatitis disease by selected newspapers in Nigeria?

In an attempt to measure the media's role in creating awareness about the hepatitis disease, this study examined the extent of coverage given to the disease by purposively selecting 4 national dailies, based on their circulation index and scope. The study revealed that in two years (being the review period for the study), the four selected newspapers did not give a significant coverage to hepatitis disease, either through news reporting or advocacy advertisement. For instance in the year 2015, 34 stories were published in all the four national tabloids examined with the Guardian taking the lead with a sum of 12 stories; the Nation newspaper -11, Daily Trust 8 and Punch newspaper -3 respectively.

Interestingly, the study found that attention to the subject was more pronounced between July and September of each year because of the annual World Hepatitis Day that is often celebrated on July $28^{\text {th }}$.

In sum, for a total of 730 days, the four national newspapers only published 55 stories on hepatitis which is one of the most deadly diseases in the World. The implications of this result mean that the low media education on Hepatitis disease will lead to a significant increase of cases of infected individuals in the Nigerian society. It is this type of thinking that made Chang, Tsai and Chang (2017) to assert that the quality of life of individuals can be improved with intensive education on hepatitis disease. Thus, there is a need for an intensive mass media education on hepatitis disease in Nigeria. 


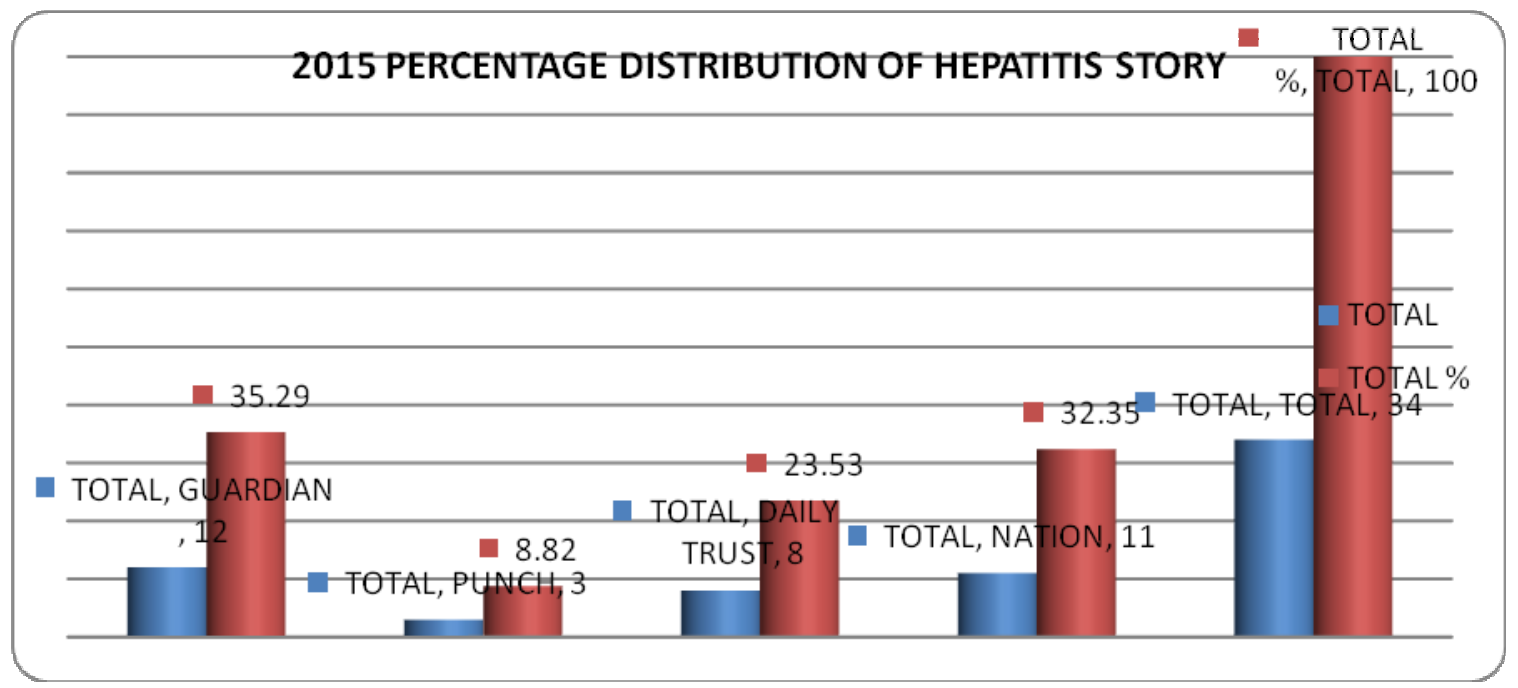

Chart 1. Percentage distribution of hepatitis stories published in the year 2015

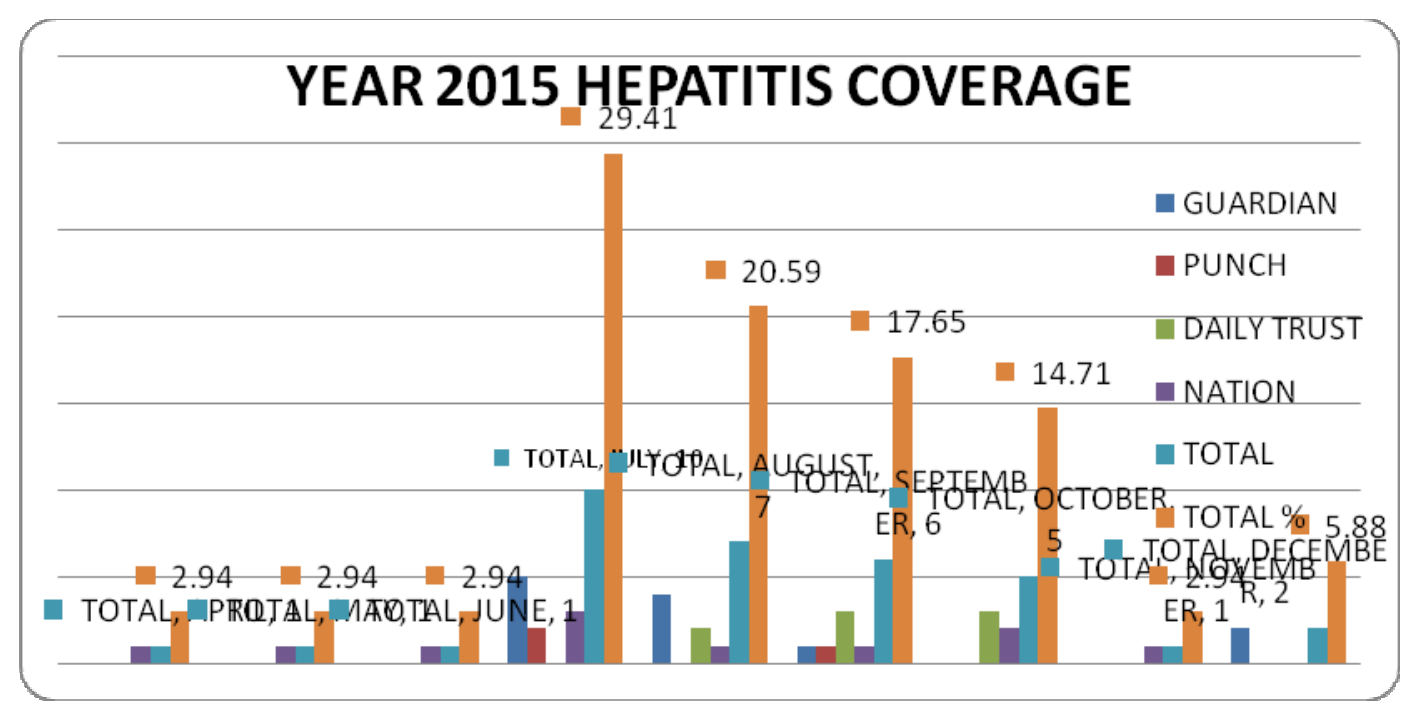

Chart 2. Monthly Percentage distribution of hepatitis coverage in the year 2015

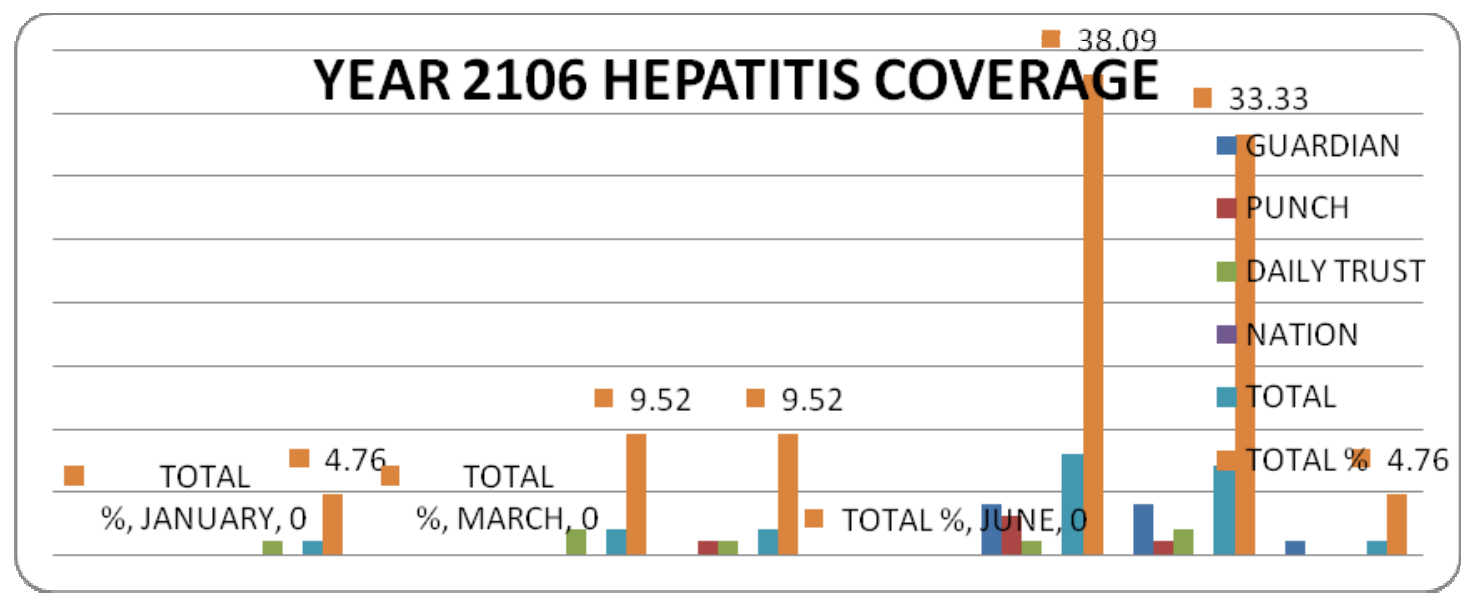

Chart 3. Monthly Percentage distribution of hepatitis coverage in the year 2016 


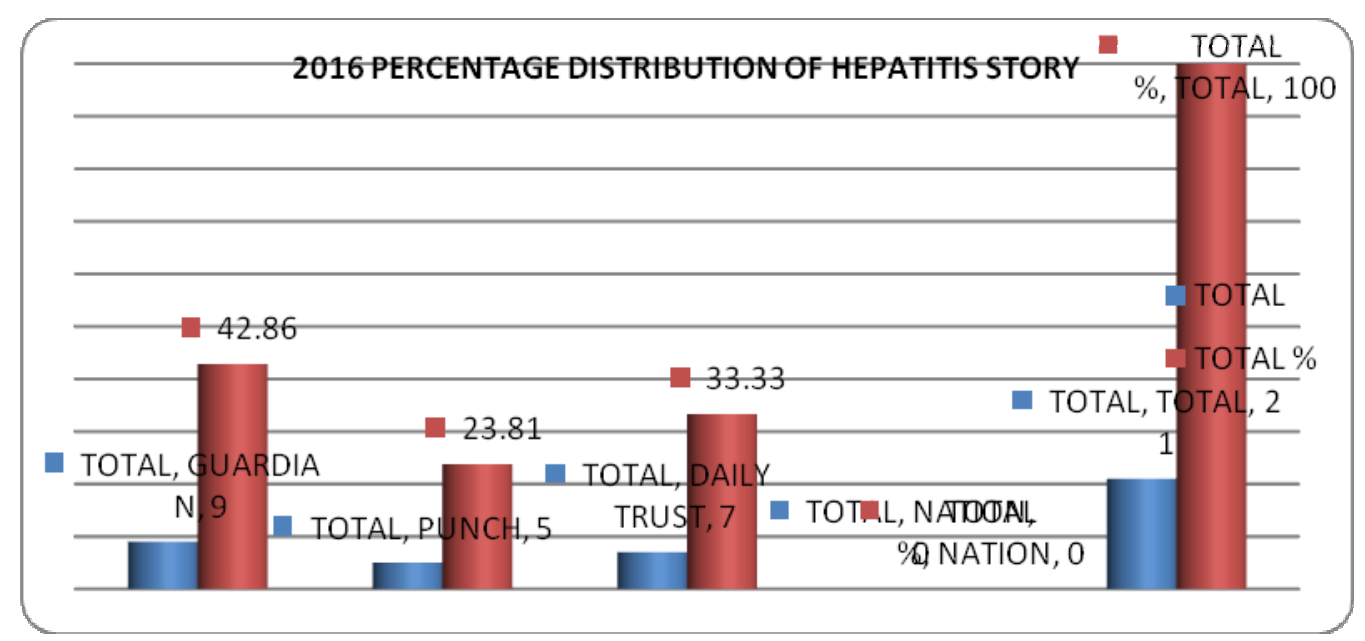

Chart 4. Percentage distribution of hepatitis stories published in the year 2016

\section{Research Question 2: What is the awareness level of Students in Ogun State Tertiary Institutions about the Hepatitis Disease?}

A total of 300 questionnaire copies were administered to students of Federal University of Agriculture, MoshoodAbiola Polytechnic and Federal College of Education, Abeokuta, Ogun State, with a return rate of 278 duly filled questionnaire.

A total of 160 respondents which accounted for $53.3 \%$ of the respondents had been previously informed about the hepatitis disease, with $40.3 \%$ of the respondents getting to know through the main stream media (television, radio, and newspaper) and $27.3 \%$ stating they got hepatitis information via the internet while the other 118 respondents claimed ignorance. Thus, there was not a significant level of awareness among the respondents about hepatitis disease.

Research Question 3: What is the knowledge level of Students in Ogun State Tertiary Institutions about the Hepatitis Disease?

The study shows that the knowledge level of students about the hepatitis disease is low, partly because of the awareness level of the respondents. $39.3 \%$ and $40.3 \%$ respondents respectively are either fairly aware or not aware at all about the contractive avenues of the hepatitis disease, and this partly explains why $36 \%$ and $34 \%$ respectively are either fairly knowledgeable or not knowledgeable at all about the consequences of the hepatitis disease. This result supports the findings of Adekanle, Ndububa, Olowookere, Ijarotimi and Ijadunola (2015), which indicated that more than 33\% had poor knowledge with 35\% not immunized against HBV. Similarly, this result corroborates the positions of GboezeEzeonu, Onoh, Okaegbe and Nwali (2015), which maintained that less than $25 \%$ knew that hepatitis is a viral infection affecting the liver. This statistics on awareness and knowledgeable are strong explanatory points on the reasons why most of the respondents $(83.3 \%)$ had not gone for medical examination to check their Hepatitis status in the last 12 months, despite involvement in sexual activities in the last 12 months (36\%), sharing sharp objects (52.7\%), non-vaccination against hepatitis disease $(87.3 \%)$ in the last 12 months.

Globally, the hepatitis disease is a major health issues, contributing a huge burden on the healthcare setup, and are a major source of human misery (Ali et al., 2011; Bakhoum et al., 2014). Knowledge, awareness and attitude play important role in improving the health status of the society as sufficient amount of knowledge about the causes, symptoms and curative measures are instrumental to keeping a healthy society.

\section{Conclusion}

The study has thus far, established that the print media have not lived up to it's responsibility of informing and educating Nigerians on the endemic nature of the hepatitis disease, with just 55 stories published by four national and widely read newspapers in two years. The respondents expressed they had little knowledge of the nature, contractive avenues, symptoms and consequences of the disease as well as the need to be tested and vaccinated against the disease.

The posture of the newspapers in paying little attention to hepatitis issue therefore reduces the hope of attaining of the Goal 3 of the Sustainable Development as enunciated by the United Nation General Assembly to engender 
healthy lives, and promote wellbeing for all ages by 2030 .

The significant relationship between health and media cannot be overstated as both deal with living things and one cannot be isolated from the other. The Nigerian media therefore needs to bring public health issues such as hepatitis to the front burner by setting the right agenda as well as infusing more interpretive schema by way of images, stereotypes, and messages in their health reports.The media in Nigeria also need to urgently align with the Health Belief Model by positively affecting the perception of the people living a sensitive and conscious life against the Hepatitis Disease

The role of the media in achieving the "Global Health Sector Strategy on Viral Hepatitis 2016-2021, towards ending Viral Hepatitis" is very imperative. It is not therefore surprising that in the first item under the five strategic direction to achieving this objective is "Information for focused action: developing a strong strategic information system to understand viral hepatitis epidemics and focus the response" The Nigerian media as a development agency therefore have a responsibility to aligning with the vision of the World Health Organisation which Nigeria is a signatory to.

\section{Competing Interests Statement}

The authors declare that there are no competing or potential conflicts of interest.

\section{References}

Agada, D. (2016, March). Dangers and realities of hepatitis. Paper presented at the meeting of Federal College of Education, Abeokuta.

Atkin, C., \& Wallack, L. (1990). Mass communication and public health. London: SAGE Publications.

Akikor, E.A., \&Erhabor, O. N. (2007). Sero-prevalence of hepatitis in children in a tertiary health institution in the Niger Delta of Nigeria.Niger J Med, 16(3), 250-251.

Blumberg, B. S. (2002). Hepatitis B: The Hunt for a killer virus. Princeton University Press, London. 264 pp

Bryant, J. T (2002). Fundamentals of media effects. New York: McGraw-Hill.

Burnett, R., Francois, G., \& Kew, G. (2005) Hepatitis B virus and human immunodeficiency virus co-infection in sub-Saharan Africa: A call for further action. Liver Int., 25, 201-213. https://doi.org/10.1111/j.14783231.2005.01054.x

Cohen, B. (1963). The press and foreign policy. Princeton, NJ: Princeton University Press

Dutta-Bergman, M. J. (2005). Theory and practice in health communication campaigns: a Critical interrogation. https://doi.org/10.1207/s15327027hc1802_1

Freimuth, V. S., \& Quinn, S. C. (2004). The contributions of health communication to eliminating health disparities. American Journal of Public Health, 94(12).https://doi.org/10.2105/AJPH.94.12.2053

Freimuth, V., Cole, G., \& Kirby, S. (2000). Issues in evaluating mass mediated health communication campaigns. Copenhagen: WHO Regional Office for Europe.

Glanz, K., Rimer, B. K., \& Lewis, F. M. (Eds.). (2002). Health behavior and health education (3rd ed.). San Francisco: Jossey-Bass.

Hall, G. (2007). Hepatitis update. Ethnicity \& Disease, (17), 40-45.

Ibezim, G., Okoroigwe, L., \&Ijioma, J. (2010). The contribution of farmer cooperative societies to agricultural production in Ikwuano Local Government Area of Abia State Paper presented at the Proceedings of the 44th Annual Conference of the Agricultural Society of Nigeria, LadokeAkintola University of Technology, Oyo State Nigeria.

Laswell, H. (1960). The structure and function of communication in society. In W. Schramm (ed.), Mass Communications. Urbana: University of Illinois Press.

Libbus, M. K., \& Phillips, L. M. (2009). Public health management of perinatal hepatitis B virus. Public Health Nurse., 26(353-361). https://doi.org/10.1111/j.1525-1446.2009.00790.x

Mowlana, H. (ed.), (2000). "Communication and development: theoretical and paradigmatic development". In A. A. Moemeka (ed.), Development Communication in Action: building understanding and creating participation, 17-37.

National Cancer Institute. (2003). Theory at a glance: A guide for health promotion practice. Washington, DC: U.S. Department of Health and Human Services. 
Nimzing, G. L., \& Simon, D. T. (2007). Management of liver disease in Nigeria. Clin Med, (7), 439-41.

Nugent, R. (2006). Youth in a global world. Washington, D.C.: Population Reference Bureau.

Odusanya, O. O., Alufohai, F. E., Menrice, F. P., Wells, R., Weil, J., \&Ahohkhai, V. I. (2005). Prevalence of Hepatitis B surface antigen in vaccinated children and control in rural Nigeria. International effect Dis, 9(3), 139-143.

Okorie, N. (2011). Mass media strategies for creating awareness of breast cancer.PublicPublic Knowledge Journal, 3(1). Retrieved from http://pkjournal.org/?page_id $=1520$

Okorie N, Oyesomi, K., Olusola, O., Olatunji R. W., \& Soola, E. (2014). Effective use of information sources for breast cancer care: interplay of mass media and interpersonal channels. Journal of African Research in Business \& Technology.

Oyero, O. S. (2010). Children: as 'invisible' and voiceless as ever in the Nigerian news media. Communication Studies, 72, 25-41. Retrievedfromhttp://www.labcom.pt/ec/07/vol2/EC07-2010-vol2.pdf

Oso, L. (2012). Press and politics in Nigeria: on whose side? LASU Inangural Lecture Series (47th ed.). Ojo, Lagos: Lagos State University Random House Unabridged Dictionary (2005). Maternity. New York: Random House.

Owens-Ibie, N. (2002). Communicating health issues in Nigeria: challenges for immunization Activities. In L. Oso (Ed.), Communication and development- a reader (pp. 229-238). Abeokuta, Nigeria: Jedidiah Publishers.

Pischke, S., Hardtke, S., \& Bode, U. (2013). Ribavirin treatment of acute and chronic hepatitis E: a single center experience. Liver International, a(33), 722-6.https://doi.org/10.1111/liv.12114

World Health Organisation. (2011). Youth and health risk: Sixty-Fourth World Health Assembly A64/25. Retrieved from http://apps.who.int/gb/ebwha/pdf_files/WHA64/A64_25-en.pdf

World Health Organisation. (2016). Hepatitis D Factsheet. Retrieved 7 October, 2016, from http://www.who.int/mediacentre/factsheets/fs280/en [Accessed]

World Health Organisation. (2016). Hepatitis E Factsheet. Retrieved 7 October, 2016, fromhttp://www.who.int/mediacentre/factsheets/fs280/en

World Health Organisation. (2016). Global health sector strategy on viral hepatitis 2016-2021.

Wisnom, C., \& Siegel, M. A. (2003) Advances in the diagnosis and management of human viral hepatitis. Dent Clin North Am, 47, 431-47. https://doi.org/10.1016/S0011-8532(03)00021-1

\section{Copyrights}

Copyright for this article is retained by the author(s), with first publication rights granted to the journal.

This is an open-access article distributed under the terms and conditions of the Creative Commons Attribution license (http://creativecommons.org/licenses/by/4.0/). 